\title{
Vocabulary Skills and Online Dictionaries: A Study on EFL Learners' Receptive Vocabulary Knowledge and Success in Searching Electronic Sources for Information
}

\author{
Marja-Leena Niitemaa \\ Department of English, University of Turku, Turku, Finland \\ Päivi Pietilä \\ Department of English, University of Turku, Turku, Finland
}

\begin{abstract}
The study reported in this article examined Finnish EFL learners' ability to search for lexical items and information in online dictionaries and on websites. The study was conducted as part of a project investigating upper secondary school students' digital skills in relation to language learning. The motivation behind the study was that in Finland, the high-stakes school-leaving examinations, including foreign language tests, are currently being digitalized. The aim of the study was to uncover the relationship between word recognition skills and the learners' ability to find lexical items and information in a series of online vocabulary tasks when the choice of the digital sources was not controlled. The results showed, for example, that overall word recognition skills and recognition of low-frequency vocabulary correlated positively with success rates in finding individual words in online dictionaries and factually accurate information on webpages, but not with finding appropriate collocations. Moreover, to succeed in $50 \%$ of the look-ups required scoring a minimum of $60 \%$ in the vocabulary levels test.
\end{abstract}

Index Terms — digital skills, EFL, online dictionaries, online reading, vocabulary recognition

\section{INTRODUCTION}

Statistics indicate that most European teenagers read webpages not only for entertainment but also for information (OECD, 2013), the percentage being as high as 91\% in Finland (Statista, 2015). Authorities in many countries have taken the initiative to integrate digital skills in the curricula to ensure that learners can use digital resources to their advantage. For example, all Nordic countries have started to implement national strategies for media literacy, so that the use of digital technology is taught as a general skill needed in all subjects as well as a tool for specific tasks. Moreover, schools provide computers with a high speed of broadband connectivity and connectedness (Nordic@BETT, 2016).

The current view on literacy highlights the ability to use written texts in real-life situations, including information presented in a visual or graphic form. For example, The Programme for International Student Assessment (PISA) defines reading literacy as "understanding, using, reflecting on and engaging with written texts, in order to achieve one's goals, develop one's knowledge and potential, and participate in society" (PISA, 2015, p. 49). This entails adequate language skills combined with multiple literacies including digital skills (Leu \& al., 2013; OECD, 2013). Digital skills refer to medium-related skills, including basic computer use and navigation across sites with menus and hyperlinks, and content-related skills, for example, the ability to search, select and evaluate information, as well as communicate and create content in digital environments (Van Dijk \&Van Deursen, 2014). Regarding language-related skills, lexical knowledge is traditionally considered one of the foundational literacy skills (Alderson, 2005; Jeon \& Yamashita, 2014; Nation, 2006; Schmitt, Jiang \& Grabe, 2011). It is reasonable to assume that content-related digital skills are closely connected with lexical knowledge, as reading and writing are often intertwined in online practices.

With respect to Finland, learning activities in language classrooms, as well as the high-stakes school-leaving examinations in foreign languages, are currently being digitalized. This entails, for example, integrating multimodal features in test tasks. At this turning point, however, teenagers' digital skills are far from adequate. Research on Finnish $9^{\text {th }}$ graders revealed that 15 -year-olds scored on average $25 \%$ of the maximum points in medium-related tests including basic computer use, and $41 \%$ in content-related tasks, such as searching for information (Kaarakainen $\&$ al., 2017). The present study set out to examine upper secondary school learners' digital skills from a language learning perspective. The aim was to investigate which online dictionaries and informational websites upper secondary school English learners use when they can choose the sources freely, and in what way successful use of online sources relates to vocabulary recognition skills. 


\section{LITERATURE REVIEW}

Looking up words has been studied from multiple perspectives, including learners' dictionary behaviour and effects on reading comprehension, writing and vocabulary retention (e.g., Atkins \& Varantola, 1998; Dziemianko, 2010; Laufer \& Hill, 2000; Laufer \& Levitzky-Aviad, 2006; Liou, 2000). However, most studies have not involved dictionaries that are freely available on the Internet. Instead, researchers have mostly exploited electronic glosses, dictionaries tailor-made for research purposes (e.g., Laufer \& Levitzky-Aviad, 2006; Peters, 2007; Tono, 2011), handheld pocket electronic dictionaries (e.g., Boonmoh, 2012), or an existing online dictionary linked to the words of the reading task at hand (Liou, 2000). Further, most studies have been conducted among university students, and the subjects' English language skills have been rather vaguely defined as intermediate or advanced. Therefore, very little is known about what younger learners do when their dictionary choices are not controlled. The present study investigated which online dictionaries and informational websites upper secondary school English learners use when they can choose the sources freely, and in what way and how successfully they use them in relation to their vocabulary recognition skills.

\section{A. Dictionaries and Reading}

Online reading for information comprises distinctive reading processes: reading to understand the problem posed in the task, locating task-relevant information, evaluating the findings, combining information from various sources, and finally, sharing the results with others. The first two stages form a bottleneck: if the learner does not comprehend the task and find the information needed, it is impossible to continue (Leu \& al.; 2013, p. 1164). Another characteristic of reading online is that different learners utilize their own individual search paths to solve the same task, and thus encounter different amounts of text.

Dictionary entries represent a special form of expository text (The DIALANG Assessment Framework; cited in Alderson, 2005, p. 126-128), and dictionary use can be viewed as reading for information. However, reading dictionary entries differs from reading websites. Firstly, webpages provide multimodal information, which may facilitate comprehension (Alderson, 2005). In contrast, online dictionaries rarely supply more than sound, as moving images may be distracting (Lew, 2012). Secondly, even short website text is contextualized and coherent, whereas dictionary entries comprise brief definitions without context, and the discourse of the usage examples is likely to be unfamiliar to learners. Thirdly, dictionary entries are mostly read to gain a quick access to the word meaning, so looking up words is ancillary to some other task, whereas websites are read also for pleasure.

\section{B. Dictionary Use}

Despite different materials and methods used, the literature on previous studies reports several common findings regarding L2 learners' dictionary behaviour. First, learners' dictionary skills are often inadequate (e.g., Boonmoh, 2012; Chan, 2014). Not knowing how to use the dictionary, learners stop searching as soon as possible, scan through the beginning of the entry and choose one of the first meanings instead of examining all the senses (e.g., Tono, 2011). Second, dictionary behaviour seems to be related to language skills. Advanced learners prefer to answer without consultation, but they succeed well in finding the target words if they search for them. Weaker learners look up more words, but they do not benefit from the dictionary because of their poor lexical skills. Thus, the frequency of search queries is not linearly related to the number of correct answers (e.g., Atkins \& Varantola, 1998; Liou, 2000; Pelttari \& Mutta, 2014). Further, many learners have difficulties when a familiar word is used in an unfamiliar sense, as they tend to believe that the meaning they know is the only one (Atkins \& Varantola, 1998; Chan, 2014).

In general, learners display a positive attitude towards using digital reference tools (e.g., Boonmoh, 2012; Dziemianko, 2012), but they do not always choose to use them. Learners may overestimate their lexical knowledge, thinking that they know the word or that they can infer the meaning (Laufer \& Yano, 2001). Some learners consider the consultation process too slow and tedious, particularly if their dictionary skills are inadequate (Boonmoh, 2012), while others find dictionary use distracting when reading longer texts for global comprehension. Moreover, the reading purpose has an impact on dictionary behaviour, so that translating and summarizing may generate more queries than reading for global meaning (e.g., Peters, 2007; Tono, 2011). The decision to use reference tools may also depend on the learner's ability to manage his or her own learning (Kalaja \& al., 2011).

Consulting online dictionaries involves several stages of decision-making: which words to search, which sources to consult, which item to select from the entry, and whether to conduct additional queries (Tono, 2011). When navigating between the task and the information sources, the learner must maintain task relevant information in the working memory. This is all the more complicated if the dictionary user works simultaneously in two or more languages. Thus, many researchers share the view that reading dictionary entries is a cognitively complex process involving multiple skills related to language knowledge, information processing and problem-solving, in other words, competences that are essential in reading comprehension in general (Tono, 2011).

\section{Dictionaries and Vocabulary}

Nation (2015) has suggested that consulting monolingual entries is possible even with small vocabularies of 2000 to 3000 words, as the word definitions are constructed using high-frequency vocabulary. On the other hand, dictionary use is a complicated process requiring lexical skills: recognizing the meanings of the words listed in the entry, reading the 
definitions, selecting the best option, and inferring the meaning even if none of the meanings offered seems appropriate (Chan, 2014; Liou 2000). Productive knowledge is needed in typing search queries without major spelling mistakes, as even expert-constructed dictionaries cannot necessarily identify misspelt words (Lew, 2012; Lew \& Mitton, 2012). It is also known that many learners find monolingual entries incomprehensible and prefer bilingual sources (e.g., Laufer \& Levitzky-Aviad, 2006). Not surprisingly, if the definition vocabulary is equally difficult as the words being looked up, the entries can be hard for learners to understand (Schmitt \& Schmitt, 2014). Moreover, the readability of dictionary entries can also be affected by various other factors, such as the number of words employed or the use of the passive voice. The information given in some online dictionaries may even be misleading (Nesi, 1998, 2012). In sum, dictionary entries are not effortless reading.

\section{THE STUDY}

The study had two objectives: firstly, to uncover EFL learners' information search processes by observing a group of upper secondary school students, and secondly, to explore the connection between lexical recognition skills and successful use of online sources. The study was deemed to be important and of current relevance, not only because of potential implications for the updating of foreign language curricula and language tests, but also in view of finding efficient ways to help learners use online resources effectively. Thus, the study addressed two questions:

1. What online dictionaries and informational websites do upper secondary school students use when they can choose the sources freely, and in what way and how successfully do they use them?

2. What is the relationship between word recognition skills and successful use of online sources?

Recent research findings have showed that teenagers' digital skills are inadequate (Kaarakainen \& al., 2017), so it was expected that locating lexical items and information online would not be easy for all learners. As lexical knowledge is commonly considered one of the central components of literacy skills (e.g., Alderson, 2005; Nation, 2006; Schmitt, Jiang \& Grabe, 2011), and as online practices involve a great deal of reading, it was hypothesized that lexical knowledge would be an important factor in consulting digital sources successfully.

\section{A. Subjects}

The 22 subjects ( 4 females, 18 males) volunteering to join the experiment were second-year students, aged 17-18, of a Finnish academically oriented and municipally maintained upper secondary school. They had previously studied L2 English for seven years (c. 600 45-minute lessons) at the comprehensive school, and c. 120 lessons at the upper secondary school. By the end of the second year, they were expected to have reached CEFR level B2 (Council of Europe, 2001). The subjects were informed that the results would not affect their course grades, but that the study would be important for designing online tests.

\section{B. Methods and Materials}

Self-reports: Before the experiment, the subjects were asked what types of online dictionaries they used, and whether language teachers had informed them about various online dictionaries and/or instructed them how to consult the dictionaries.

Vocabulary: Vocabulary recognition skills were tested using the Vocabulary Levels Test (Schmitt, Schmitt \& Clapham, 2001; Nation, 1983) with 30 items in the $2^{\text {nd }}, 3^{\text {rd }}, 5^{\text {th }}$ and $10^{\text {th }}$ frequency bands (henceforth the VLT). In addition, the $10^{\text {th }}$ frequency band (henceforth $K_{-} 10$ ) was analyzed separately to examine the role of rare words in using online sources.

Online Tasks: The subjects performed altogether three online tasks on three separate occasions. The tasks were conducted using similar desktop computers in a computer room which had been booked for 75 minutes. The subjects had free access to online dictionaries and search engines, but using mobile phones was not allowed during the sessions. The individual working process of each student was videoed using freely downloadable software, CamStudio. The subjects were instructed in how to use the program and encouraged to ask for assistance should any technical problems occur.

The online tasks represented different textual genres and task types. Tasks 1 and 3 consisted of gap-filling. The subjects were instructed to fill in the gaps following L1 (Finnish) prompts so that the additions fitted the context and register. Task 1, with eight target items, was a promotional letter to a potential customer from a company providing investment services. Task 3, with 13 target items, was a blog of a young boy reflecting on the advantages and disadvantages of obtaining a college degree. One noun (annuity) and one pragmatic formula (a formal letter ending) were categorized as search for factual information, as finding the answers was expected to require consulting also other sources besides dictionaries. All the other target items included finding or checking meanings of individual words or phrases. Task 2 was an experiment to simulate a real-world task. It was based on poorly written instructions for the use of a laser pointer. The subjects were asked to proofread, edit, and rewrite the text. The text included eight inappropriate word choices, but they were not indicated in any way.

No standardized tests being available, the tasks were designed by the researcher. Gap-filling was chosen for several reasons: it has been used in dictionary research before (e.g., Atkins \& Varantola, 1998; Dziemianko, 2010); the subjects were familiar with the test type; it integrates reading and writing, which is typical of online practices (Van Dijk \& Van 
Deursen, 2014); and the researcher was able to choose the target items so that they represented various degrees of objective complexity (Singer \& al., 2012), involving several queries, choosing from multiple alternatives and meanings, or searching for a rare word or a common word with an unfamiliar meaning. In contrast, a non-complex target would be easy to find if the entry offered only one translational counterpart or more than one suitable option. A seemingly simple target item may, however, be subjectively complex (Singer \& al., 2012), for example, due to the learner's inadequate word recognition skills or low motivation to carry out the task.

The task texts were analyzed for word frequencies using the lexical profiler at Lextutor.ca (Cobb, 2013). It was found that $96 \%$ of the vocabulary in the gap-filling task consisted of high-frequency words from the $1^{\text {st }}$ to the $3^{\text {rd }}$ frequency bands, and $2-3 \%$ of the words were mid-frequency vocabulary from the $4^{\text {th }}$ to the $8^{\text {th }}$ frequency bands (see Schmitt $\&$ Schmitt, 2014 for the definitions of frequency). The remaining words were proper nouns. The proportion of midfrequency vocabulary was slightly higher $(7 \%)$ in the editing/rewriting task. Whenever possible, the targets in the gapfilling tasks were compared against the skill level rating in the CEFR ${ }^{1}$. Interestingly, some targets were profiled as high frequency words by Lextutor, whereas the CEFR rating referred to a higher competence level.

Assessment: Successful use of online sources was defined as an ability to navigate across online sites with menus and links (medium-related skills), to locate and select the items required and to evaluate whether the findings fitted the context (content-related skills). The responses were first divided into answers involving look-ups and those without consulting any sources, and then categorized as fully successful, partly successful, or unsuccessful. The criterion of a fully successful choice was that the meaning and use were accurate and the word was appropriate for the context and register. All contextually suitable variants were accepted, e.g., funds instead of assets, whereas money was considered too vague and informal. If the meaning was inaccurate, the word was not a common collocate, or if it was in a wrong form, it was counted as partly successful. For example, the collocation make a mistake fitted the context only in the past tense. This may be considered overly strict, but on the other hand, the subjects had ample time to check their answers using online sources. A word or phrase that did not fit the context or register, or came with a wrong meaning, was rated unsuccessful, e.g., *examination instead of degree in the sense of academic qualification.

\section{RESULTS}

In the two subsections that follow, the results pertaining to the two research questions are provided. Firstly, the subjects' self-reports on their dictionary use and their look-up practices are presented (RQ 1), and secondly, the success rates in the online tasks are analyzed and compared across the scores in the VLT and $K_{-} 10$ (RQ 2). Although the focus of the study was on the consultation of digital sources, the answers given without consultation are also reported, as they comprised over half of all the responses (52\%). The correlational analyses were computed using SPSS Statistics 23.

A. RQ 1: What Online Dictionaries and Informational Websites Do Upper Secondary School Students Use When They Can Choose the Sources Freely, and in What Way and How Successfully Do They Use Them?

Self-reports: Before the experiment, the subjects were asked whether they had been taught how to use online dictionaries and what types of dictionaries they usually consulted. The responses revealed that the majority (18 out of 22) had received neither information nor training, whereas four students had been given some information about the possibility of using online sources but no training. The majority (14) reported using bilingual (Finnish-English-Finnish) online sources, two subjects consulted monolingual dictionaries, whereas three subjects used both.

Sources consulted: In the gap-filling tasks, the subjects consulted eleven free multilingual Internet dictionaries ${ }^{2}$ (eudict.com, Free Dictionary, ilmainensanakirja.fi, Kaannos.com, Sanakirja.org, suomienglantisanakirja.fi, suomisanakirjat/sivistyssanakirja, Taloussanakirja, Wiktionary, Wikiword, WordReference). No expert-constructed learners' dictionaries were used. In addition, the subjects used one translating tool, Google Translate, one search engine, Google.com and five other informational sites, Forum.virtualtourist.com, Investopedia, Lainatieto.fi, UsingEnglish.com and Wikipedia either in English or Finnish. In the editing and rewriting task, the queries were limited to Sanakirja.org, Google Translate and Google.com.

The videos demonstrated that the subjects had one primary source, which was either the only source they consulted or the source they consulted first. The most widely used primary sources were Google Translate and Sanakirja.org. In gap-filling, Google Translate was the most frequently used source (120 times) and Sanakirja.org was the most frequently consulted dictionary (109 times). All the other sources were used from one to thirteen times. Nine subjects out of 22 consulted only one source, four participants had two sources, three subjects used three sources and six students visited from four to nine different sites.

Words looked up: In gap-filling, the range of the words looked up was from 1 to 20. Four targets were searched by at least half of the subjects: 19 subjects out of 22 searched the adjective entrepreneurial, 14 subjects queried the colligation keen on developing and the noun curriculum, and half of the subjects looked up the prepositional verb bump

\footnotetext{
${ }^{1}$ Information on BNC-COCA-25 frequency bands was retrieved from Lextutor.ca., and the CEFR rating from Cambridge Dictionary Online and English Vocabulary Profile.

${ }^{2}$ The sources with Finnish titles, ilmainensanakirja.fi, Kaannos.com, Sanakirja.org and suomienglantisanakirja.fi, are free multilingual dictionaries; suomisanakirjat/sivistyssanakirja, provides synonyms and academic vocabulary; Taloussanakirja, focuses on economic vocabulary; Lainatieto.fi, provides information about loans.
} 
into. In contrast, the collocation make a mistake and the verb form caught were searched rarely. The latter was searched to check the spelling or the tense to replace forms like *cought or *cathed.

Most targets were queried once. In case of objective and/or subjective complexity, more queries were conducted per target item. For example, although an unknown word, curriculum was easy to find, as the sources offered only one option, whereas the adjective entrepreneurial required a more complicated search path. However, five subjects could find it with one query, eight subjects made two queries, and three subjects conducted from three to five successive queries. Also, searching for the collocation make an appointment and an explanation for annuity generated three or more queries.

In the editing and rewriting task, the item queried the most was the verb becomes with 14 look-ups. This common verb is usually difficult for Finnish learners, as the senses of come and become are not differentiated in Finnish. In contrast, the majority did not notice the erroneous collocation *keep a presentation in the text, and only two subjects searched and found the correct combination give a presentation. The reason for this error is probably that the Finnish verb for 'keep' is used in the corresponding L1 collocation. Ten students did not recognize the meaning of the noun deafness, which was used in a wrong context. Although a common word with only one meaning, it may have been unknown to the subjects.

Finally, a correlation was computed between the VLT score (vocabulary recognition) and the number of words searched by the subjects. (For the actual VLT scores, see the next section on RQ 2). The highly significant negative correlation $(-.632 ; p=.002)$ suggested that the subjects who scored high in the VLT looked up fewer words. Moreover, when the number of successive queries was examined, the negative correlation $(-.507 ; p=0.16)$ showed that a high $V L T$ score indicated also fewer successive queries for the same item.

Look-up practices: The video recordings revealed that the subjects differed in terms of digital skills, look-up practices, the degree of language awareness, the amount of reading while searching, and how persistently they conducted queries. The recordings demonstrated that several participants lacked basic technical skills. For example, inefficient typing complicated the querying process to the extent that the "did you mean" function in the dictionary could not suggest any contextually suitable alternatives. Neither could all the subjects use the copy-and-paste feature. One subject chose a 27 -word long search result, but, unable to copy and paste the text, had to go 18 times from the entry to the task and back again. In contrast, skilled searchers often had their primary source opened in its own window next to the task, which allowed quick navigation between the entry and the task. Moreover, the observations showed that dictionary skills were inadequate. In the survey, most subjects reported using bilingual (Finnish-English-Finnish) online dictionaries, but in the recordings the subjects actually consulted multilingual sources, which they exploited them bilingually ignoring the monolingual features provided in them.

The subjects differed also in content-based skills. Skilled searchers crosschecked the finding, exploiting both the bilingual and monolingual features in the dictionary. They searched from L1 to L2 and vice versa checking the definitions from English-English sources, and studied also the additional information provided. For example, one subject filled a gap first with funds without looking up the word. However, he decided to check the meaning, got 16 alternatives, scrolled down for the definition of funds, read the example sentence and then concluded that the meaning was appropriate. In contrast, low-skilled subjects often chose the first alternative in the entry. This resulted in a wrong choice particularly when the prompt and/or the target word had multiple meanings, e.g., *placement instead of investment. Moreover, some learners accepted readily the phrase generated by Google Translate, even if it did not make any sense, such as *offer substitute advisory officer instead of the correct offer or provide investment advice. Neither did they continue searching even if they realized that the first search result was not suitable. For example, having queried a bilingual source for annuity, one subject gave the (wrong) meaning in L1 and wrote that nothing else was found. Some subjects, contrary to the prompt, copied explanations word by word from the source.

It was observed that the amount of text read by the subjects varied considerably. Searching for a formal letter ending, one subject queried formal letter first via Google.com, read the search results, found suggestions yours faithfully and yours sincerely, then continued querying two other sites, UsingEnglish.com and WordReference.com, and encountered the same suggestions with slightly different explanations. Finally, the subject examined the images under formal letter ending, which verified the previous search results. Another subject read hardly any text. He remembered sincerely, wrote that down, searched for the L1 meaning for this word, apparently became confused with the literal meaning, and decided to end the formal letter with yours.

Most subjects tended to rely on what they knew about the topic, but were unable to rethink when finding contradictory information. A case in point was searching a contextually appropriate explanation for annuity. Most subjects did not read the text of the task carefully enough to discover the contextual clues. Having probably encountered the L1 cognate in the context of a bank loan, it seemed difficult for some students to start thinking of an insurance policy instead. This is what happened to a participant who persisted with the idea of a bank loan, although he had encountered the contextually suitable meaning several times during a complicated search path via two dictionaries and three websites.

When checking their word choices, some subjects decided to change a fully acceptable answer for another appropriate choice, e.g., have an impact on your investment was changed for affect your investment, an entrepreneur kind of person for entrepreneurial or continued spreading for kept on spreading. A kind of "tip of the tongue" 
phenomenon (Aitchison, 1994) was also observed. Some students knew approximately what the lexical item they needed would sound or look like before checking it, e.g., *revolob instead of develop, *sincinerally instead of sincerely, or *entrenepour instead of entrepreneur. Moreover, most of the students filled the blanks in the order of appearance, while six subjects changed the working order postponing a difficult target, such as entrepreneurial, for later.

In the editing and rewriting task, the targeted test items were not indicated. The subjects were unfamiliar with this task type and did not know how to exploit online sources when solving it. Most subjects began reading the text and paused when they suspected that a word did not fit the context. When pausing only for a short stretch of time, the subject usually changed the word immediately, but at this point, some subjects changed a correct choice to an inappropriate alternative. Another approach was to change the sentence structure so that no look-up was needed.

Table I gives a summary of two profiles of learners, one with good and the other with poor digital skills, based on the results of RQ 1 of the present study.

TABLE I.

DIGITAL SKILL PROFILES

\begin{tabular}{|c|c|c|}
\hline & Skilled and productive & Low-skilled and ineffective \\
\hline Mechanics & $\begin{array}{l}\text { Adequate digital skills } \\
\text { - Types in the query quickly and efficiently } \\
\text { - Exploits the spell checker } \\
\text { - Uses the copy \& paste function } \\
\text { - Keeps several windows open simultaneously }\end{array}$ & $\begin{array}{l}\text { Inadequate digital skills } \\
\text { - Types in the query with several spelling mistakes } \\
\text { - Does not exploit the spell checker } \\
\text { - Does not know how to use the copy \& paste function }\end{array}$ \\
\hline \multirow{2}{*}{$\begin{array}{l}\text { Dictionary use } \\
\text { Locating } \\
\text { information } \\
\text { Evaluating } \\
\text { information }\end{array}$} & $\begin{array}{l}\text { Multifaceted use of sources } \\
\text { - Uses two or more information sources } \\
\text { - Uses bilingual and monolingual information } \\
\text { - Exploits additional information } \\
\text { - Persistent. Conducts successive queries when needed }\end{array}$ & $\begin{array}{l}\text { Limited use of sources: } \\
\text { - Uses one primary information source } \\
\text { - Uses bilingual information } \\
\text { - Does not read additional information } \\
\text { - Gives up easily. Stops querying if the item is not found } \\
\text { immediately }\end{array}$ \\
\hline & $\begin{array}{l}\text { - Compares the alternatives } \\
\text { - Crosschecks the findings }\end{array}$ & $\begin{array}{l}\text { - Chooses the first or one of the first alternatives in the entry } \\
\text { - Does not crosscheck the findings }\end{array}$ \\
\hline $\begin{array}{l}\text { Language } \\
\text { awareness }\end{array}$ & $\begin{array}{l}\text { High degree of language awareness } \\
\text { - Aware of register and polysemy, and knows that certain } \\
\text { words collocate }\end{array}$ & $\begin{array}{l}\text { Low degree of language awareness } \\
\text { - Not aware of register or polysemy, and does not know that } \\
\text { certain words collocate }\end{array}$ \\
\hline Reading & $\begin{array}{l}\text { - Reads carefully. Highlights the task relevant parts or moves } \\
\text { the cursor along the lines }\end{array}$ & $\begin{array}{l}\text { - Reads carelessly. Moves the cursor all over the entry } \\
\text { without focusing on the task-relevant parts }\end{array}$ \\
\hline
\end{tabular}

In sum: The video observations related to RQ 1 (What online dictionaries and informational websites do upper secondary school students use when they can choose the sources freely, and in what way and how successfully do they use them?) revealed several features about the subjects' digital skills. Firstly, they confirmed that most subjects had not received proper instruction in using online dictionaries or information about the features of various types of dictionaries. No expert-constructed learner's dictionaries were consulted. A typical subject used one dictionary as a primary source, but was not motivated to exploit all the features provided in it or did not know how to do so due to inadequate skills in searching and locating online information. Secondly, the amount of text read by the subjects varied considerably. Skilled subjects searched several sites, crosschecking their findings before decision-making, while low-skilled subjects hardly read any text. Thirdly, content-related skills, such as formulating queries, selecting information and evaluating search results, were related to lexical knowledge, as low-skilled subjects tended to choose the first option in the entry, and moreover, accepted readily the expressions generated by the translation tools. Fourthly, in line with previous findings, the subjects scoring high in the VLT looked up fewer words and conducted fewer successive queries. Finally, previous knowledge had a controversial role, as some lexically skilled subjects relied on what they knew, although contextual clues and online sources indicated otherwise.

\section{B. RQ 2: What Is the Relationship between Word Recognition Skills and Successful Use of Online Sources?}

In the gap-filling tasks, $48 \%$ of the responses involved using online sources. Nearly half of the look-ups were fully successful, one third were partly successful, and one fourth of the answers failed (Table II). Expectedly, the success rate was higher in finding individual lexical items than in finding formulaic sequences.

TABLE II.

SUCCESS RATES IN ONLINE GAP-FILLING

\begin{tabular}{|l|l|l|l|l|l|l|l|l|l|}
\hline \multirow{2}{*}{ Success } & All items & \multicolumn{2}{|l|}{ Individual words } & Formulaic sequences & \multicolumn{2}{l|}{ Factual information } \\
\cline { 2 - 10 } & Frequency & $\%$ & Frequency & $\%$ & Frequency & $\%$ & Frequency & $\%$ \\
\hline Fully successful & 71 & 43 & 30 & 56 & 38 & 39 & 3 & 20 \\
\hline Partly successful & 54 & 33 & 11 & 20 & 44 & 42 & 3 & 20 \\
\hline Unsuccessful & 40 & 24 & 13 & 24 & 18 & 19 & 9 & 60 \\
\hline Total & 165 & 100 & 54 & 100 & 100 & 100 & 15 & 100 \\
\hline
\end{tabular}

The two items including factual information appeared to be the most difficult to find, as more than half of the answers $(60 \%)$ failed. In the editing/rewriting task, only $13 \%$ of the answers included consulting sources. The proportion of fully successful answers was $48 \%$, whereas $35 \%$ failed. Due to the small number of observations, this task was not analyzed further. 
The subjects' success rates in the VLT test (word recognition) and separately in $K_{-} 10$ (infrequent vocabulary) are presented in Table III.

TABLE III.

PERFORMANCE IN THE VLT AND $K \_10$

\begin{tabular}{|l|l|l|}
\hline & VLT $(\max .120)$ & K_10 $(\max .30)$ \\
\hline Mean & 80.41 & 14.27 \\
\hline SD & 30.27 & 6.95 \\
\hline Min. & 24.00 & 5.00 \\
\hline Max. & 115.00 & 27.00 \\
\hline
\end{tabular}

To investigate the relationship between word recognition skills and successful use of online sources, correlations (Pearson's $r$ ) were first computed between the gap-filling results and the scores in the VLT, and then between the gapfilling results and $K_{-} 10$ (see Table III). The number of look-ups conducted by the subjects differed considerably, the range being from 1 to 20 . Thus, the values were weighted by the frequency of items looked up, and also by the frequency of successive queries per target item.

Finding Individual Words: A positive moderate correlation $(r=.334)$ existed between the VLT score and fully successful look-ups. Partly successful answers showed a negative moderate correlation $(r=-.359)$ with the VLT. Unsuccessful answers had a stronger negative correlation with the $V L T$ score $(r=-.537)$. Regarding infrequent vocabulary, a positive correlation was observed between $K_{-} 10$ and fully successful answers $(r=.255)$, a negative correlation between $K_{-} 10$ and partly successful answers $(r=-.313)$, and a negative but stronger correlation between $K \_10$ and unsuccessful answers $(r=-.616)$. All the correlations were highly significant $(p=.001)$. Conducting successive queries for the same item did not strengthen the correlations.

Finding Formulaic Sequences: All the correlations were negative; weak between the VLT and fully successful findings $(r=-.236)$, strong between the VLT and partly successful answers $(r=-.815)$, and moderate between the VLT and unsuccessful findings $(r=-.511)$. The connections with rare words were also negative: the correlation between $K_{-} 10$ and fully successful findings was weak $(r=-.212)$, strong between $K_{-} 10$ and partly successful answers $(r=$ $-.730)$, and moderate between $K_{-} 10$ and unsuccessful findings $(r=-.561)$. All the correlations were highly significant $(p=.001)$. Conducting successive queries for the same item had a minimal effect on the correlations.

Finding Factual Information: The correlation between the VLT and fully successful information search was positive and moderate $(r=.308)$, but this time the correlation was slightly stronger $(r=.323)$ when successive queries were conducted, and the VLT correlated positively also with partly successful answers $(r=.396)$ in contrast to the former analyses. The correlation between the VLT and unsuccessful findings was negative $(r=-.516)$. The correlations were highly significant $(p=.001)$.

Regarding low-frequency words, the correlation between $K_{-} 10$ and fully successful findings was positive but weak ( $r$ $=.172, p=0.05)$. Unexpectedly, the connection between $K_{-} \overline{10}$ and partly successful findings was positive and fairly high $(r=.582)$, and even slightly stronger when successive queries were made $(r=.593)$. The correlation between $K_{-} 10$ and unsuccessful answers was negative $(r=-.571)$. These latter correlations were highly significant $(p=.001)$.

Overall, the analyses of the subjects' word recognition skills and using online dictionaries and other digital sources revealed that to succeed in $50 \%$ of the look-ups required scoring $60 \%$ in the VLT at the minimum. This would correspond to a vocabulary size of roughly 6000 words $^{3}$. Only one participant succeeded with a smaller score, whereas five subjects did not get half of the look-ups correct even with a score over $60 \%$.

Answers without consulting sources: Regarding answers given without consulting any online sources, it was found that the $V L T$ scores correlated strongly with fully successful individual words $(r=.776)$ as well as with fully successful collocations $(r=.754)$. The correlations were highly significant $(p=.000)$. In contrast, the correlation between the VLT and responses requiring factual information was positive but non-significant $(r=.384 ; p=.078)$. Regarding recognition of rare words, strong correlations were observed between $K \_10$ and fully successful individual lexical items $(r=.697 ; p$ $=.000)$, as well as between $K_{-} 10$ and fully successful collocations $(r=.751 ; p=.000)$. Moreover, $K_{-} 10$ scores correlated positively with responses requiring factually accurate information $(r=.450 ; p=.036)$.

In sum: The analyses for RQ 2 (What is the relationship between word recognition skills and successful use of online sources?) revealed a tendency that better word recognition skills were related to successful use of dictionaries and other online sources, and vice versa, the lower the vocabulary score the more unsuccessful answers were produced. Overall, to succeed in $50 \%$ of the look-ups required a score over $60 \%$ in the $V L T$, which is considerably more than suggested by Nation (2015) with respect to using monolingual dictionaries.

The type of target items influenced the consultation process, so that finding individual words and factually accurate information were more closely related to vocabulary knowledge than finding collocations. Looking up word combinations required awareness of the fact that certain words collocate, and extra effort was needed in the search, such as scrolling down for examples and additional information.

The importance of lexical knowledge in using online sources was highlighted by the fairly high negative correlations between the vocabulary scores and the consultation results that failed. But why was the correlation between the

${ }^{3}$ The rough estimation was calculated applying the method in Laufer and Ravenhorst-Kalovski (2010: 21). 
vocabulary scores and finding the right individual words in dictionaries only moderate? Firstly, the consultation process depended largely on medium- and content-related digital skills. Dictionary entries are difficult to read without knowing how the dictionary functions and what features it provides; even brief definitions may contain unknown words, and additional information is scattered in different locations, which requires scrolling down and navigating across hyperlinks. Secondly, most of the subjects with the highest word recognition skills answered without consulting any sources. This was evidenced by the strong correlations between vocabulary scores and correct individual words and phrases given without consultation.

With respect to the role of low-frequency vocabulary, positive correlations were found between recognition of rare words and finding individual words in dictionaries, and between rare words and finding factual information, but the connections were weak. Unexpectedly, recognition of rare words had a remarkably high positive correlation with factual information which was only partly successful. The finding may indicate that even partial knowledge of infrequent words can facilitate global comprehension when reading texts on informational sites. Furthermore, a connection was found between knowledge of rare words and factual information given without consulting sources, which may indicate that the students who know rare words also have more general knowledge.

\section{DISCUSSION}

The present study observed a group of Finnish EFL learners using online dictionaries and informational webpages in two different types of task, and examined the relationship between word knowledge and successful use of online sources. The findings indicated that vocabulary recognition played an important role in every stage of conducting online tasks, and overall, to succeed in $50 \%$ of the queries required scoring at least $60 \%$ in the vocabulary test.

Regarding the first stage in online reading, i.e., understanding the problem, several subjects did not know how to approach the editing and rewriting assignment simulating a real-world task. Thus, these results were not analyzed due to the small number of observations. In contrast, everyone was able to perform the gap-filling tasks. However, some subjects failed to notice contextual clues provided in the familiar task type. Most of the subjects had received no training in dictionary consultation. Consequently, they were unaware of the range of dictionaries available, and unfamiliar with the features in the dictionaries they used, or unable to take advantage of them. Further, the observations revealed inadequate medium-related and content-related digital skills; a lack of basic skills made the use of online sources slow and inefficient and hindered the navigation across sites. Regarding language skills, quick vocabulary recognition was needed when selecting information, consulting monolingual features in dictionaries and evaluating search results, whereas typing and reformulating queries required also productive word knowledge. Accordingly, the higher the vocabulary recognition score, the better the subject succeeded in locating individual target words and finding factually accurate information. In contrast, the subjects scoring low in the vocabulary test often chose the first option in an entry without checking the meaning, and took the suggestions generated by the translation tools at face value.

Previous research has found that learners who score high points in vocabulary tests conduct fewer queries. In the present study, the difference in the number of queries was significant only between the subjects with the lowest and highest vocabulary points, as the look-up frequencies seemed to be affected also by other factors, for example, individual choice to use the affordances. As one subject with a high vocabulary score put it, searching for words was interesting. It was also observed that conducting several queries for the same item did not necessarily improve the results in finding individual words and phrases, but helped when searching for factually accurate information.

Collocations were both subjectively and objectively complex targets, and thus, more difficult to locate. Either the dictionary did not provide the phrase, or detecting it required scrolling down and extra clicking for additional information. Finding formulaic sequences was also largely affected by the degree of language awareness, that is, being aware that common words collocate or that formal and informal phrases are not the same. Not finding the target collocation, some subjects translated it verbatim from L1, so, not surprisingly, the correlation between the vocabulary test score and finding phrases remained negative. When combining information from various sources, the subjects needed good working memory to evaluate the details provided simultaneously in different locations. In the searching process, most subjects relied on their previous knowledge, even if the contextual clues did not support what they knew. Thus, ability to evaluate one's previous knowledge was crucial when combining information and encountering contextual clues.

In sum, the findings showed that successful use of online sources requires familiarity with different types of dictionaries, ability to exploit all the features provided in them, knowledge of certain central concepts, such as register, collocation and polysemy, and furthermore, substantial vocabulary knowledge combined with adequate digital skills. This is what teachers could explain to those EFL learners who wonder why they have to study words, when they can always look them up.

\section{CONCLUSION}

The present study investigated which online dictionaries and informational websites Finnish upper secondary school English learners used when they could choose the sources freely, and in what way and how successfully they used them. 
Moreover, the study aimed at discovering the role of vocabulary recognition skills in using electronic dictionaries and online sources for finding words and factual information. The main findings were the following:

- Vocabulary recognition skills correlated positively with locating and evaluating individual words and finding factual information, but not with finding collocations.

- Word knowledge was particularly important when the learner needed to select and evaluate the search results, infer the appropriate meaning in an entry, generate and reformulate search queries, and read and combine information from various sources.

- To succeed in $50 \%$ of the look-ups required scoring at least $60 \%$ in the vocabulary test.

- Conducting online tasks successfully required multiple skills: quick vocabulary recognition skills, knowledge of how online dictionaries function, persistence in formulating and conducting queries, familiarity with the concepts of register, collocating words and polysemy, critical attitude towards previous knowledge, and digital skills including basic computer use and ability to search, locate, select, combine, and evaluate information.

With respect to pedagogical implications, dictionary skills should be included in foreign language curricula as an essential part of literacy. EFL learners need a language teacher to introduce different types of dictionaries, demonstrate how the features in online dictionaries function, organize opportunities to learn how to search, locate, select and evaluate information, and more importantly, to share their search results and compare their individual search paths with those of their peers.

\section{REFERENCES}

[1] Aitchison, J. (1994). Words in the mind. An introduction to the mental lexicon. Oxford: Blackwell.

[2] Alderson J.C. (2005). Assessing reading. New York: Cambridge University Press.

[3] Atkins, B.T.S (ed.) (1998). Using dictionaries: Studies of dictionary use by language learners and translators. Tubingen: Niemeyer.

[4] Atkins, B.T.S. \& K. Varantola (1998). Language learners using dictionaries: the final report on the EURALEX/AILA research project on dictionary use. In Atkins (ed.), Using dictionaries: Studies of dictionary use by language learners and translators. Tubingen: Niemeyer, 21-81.

[5] Boonmoh, A. (2012). E-dictionary use under the spotlight: students' use of pocket electronic dictionaries for writing. Lexikos $22,43-68$.

[6] CamStudio. (n.d.). https://camstudio.en.softonic.com/?ex=DSK-347.0 (accessed 20/1/2017)

[7] Chan, A. (2014). How can ESL students make the best use of learners' dictionaries? English Today 30.3, 33-37. doi:10.1017/S0266078414000248.

[8] Cobb, T. (2013). Lextutor. www.lextutor.ca/ (accessed 21/1/2017)

[9] Council of Europe (2001). Common European Framework of Reference for languages: learning, teaching, assessment. Cambridge: Cambridge University Press.

[10] Dziemianko, A. (2010). Paper or electronic? The role of dictionary form in language reception, production and the retention of meaning and collocations. International Journal of Lexicography 23.3, 257-273. doi:10.1093/ijl/ecp040.

[11] Dziemianko, A. (2012). On the use (fullness) of paper and electronic dictionaries. In Granger \& Paquot (eds.), Electronic lexicography. Oxford: Oxford University Press, 319-337.

[12] Granger, S. \& M. Paquot (eds.) (2012). Electronic lexicography. Oxford: Oxford University Press.

[13] Jeon, E. \& J. Yamashita (2014). L2 reading comprehension and its correlates: a meta-analysis. Language Learning 64.1, 160-212. doi: 10.1111/lang.12034.

[14] Kaarakainen, M., Kaarakainen, S., Tanhua-Piiroinen, E.,Viteli, J., Syvänen, A. \& A. Kivinen. (2017). Digiajan peruskoulu 2017. Tilannearvio ja toimenpidesuositukset. Valtioneuvoston selvitys- ja tutkimustoiminnan julkaisusarja $72 / 2017$. [Comprehensive school digitalisation: Status review and recommendations for action for 2017, English abstract]. http://www.utu.fi/fi/Ajankohtaista/Uutiset/Documents/Digiajan\%20peruskoulu\%202017\%20\%E2\%80\%93\%20Tilannearvio\%2 0ja\%20toimenpidesuositukset.pdf (accessed 1/12/2017).

[15] Kalaja, P., Alanen, R., Palviainen, ̊̊. \& H. Dufva. (2011). From milk cartons to English roommates: context and agency in L2 learning beyond the classroom. In P. Benson \& H. Reinders (eds.), Beyond the language classroom. Basingstoke: Palgrave Macmillan, 47-58.

[16] Laufer, B. \& M. Hill (2000). What lexical information do L2 learners select in a CALL dictionary and how does it affect word retention. Language Learning \& Technology 3.2, 58-76.

[17] Laufer, B. \& Y. Yano (2001). Understanding unfamiliar words in a text: do L2 learners understand how much they don't understand? Reading in a Foreign Language 13.2, 549-564.

[18] Laufer, B. \& T. Levitzky-Aviad. (2006). Examining the effectiveness of "bilingual dictionary plus" - a dictionary for production in a foreign language. International Journal of Lexicography 19.2, 135-155. doi:10.1093/ijl/eck006.

[19] Laufer, B. \& G. Ravenhorst-Kalovski. (2010). Lexical threshold revisited: lexical text coverage, learners' vocabulary size and reading comprehension. Reading in a Foreign Language 22.1, 15-30.

[20] Leu, D.J., Kinzer, C.K., Coiro, J., Castek, J. \& L.A. Henry. (2013). New literacies: a dual-level theory of the changing nature of literacy, instruction, and assessment. In D.E. Alvermann, N.J. Unrau \& R.B. Ruddell (eds.), Theoretical models and processes of reading. Newark, DE: International Reading Association, 1150-1181. DOI: 10.1598/0710.42.

[21] Lew, R. (2012). How can we make electronic dictionaries more effective? In Granger \& Paquot (eds.), Electronic lexicography. Oxford: Oxford University Press, 343-361.

[22] Lew, R. \& R. Mitton (2012). Online English learners' dictionaries and misspellings: one year on. International Journal of Lexicography 26.2, 219-233. doi:10.1093/ij1/ecs016. 
[23] Liou, H. (2000). The electronic bilingual dictionary as a reading aid to EFL learners: research findings and implications. Computer Assisted Language Learning 13, 467-476.

[24] Nation, P. (1983). Testing and teaching vocabulary. Guidelines 5, 12-25.

[25] Nation, P. (2006). How large a vocabulary is needed for reading and listening. The Canadian Modern Language Review 63.1, 59-82.

[26] Nation, P. (2015). Principles guiding vocabulary learning through extensive reading. Reading in a Foreign Language 27.1, $136-145$.

[27] Nesi, H. (1998). Defining a shoehorn: learners' dictionary entries for concrete nouns. In Atkins (ed.), Using dictionaries: Studies of dictionary use by language learners and translators. Tubingen: Niemeyer, 159-178.

[28] Nesi, H. (2012). Alternative e-dictionaries: Uncovering dark practices. In Granger \& Paquot (eds.), Electronic lexicography. Oxford: Oxford University Press, 363-378.

[29] Nordic@BETT (2016). How far are the Nordic countries in using ICT to teach students in primary and lower secondary school $21^{\text {st }}$ century skills? www.emu.dk/sites/default/files/Nordic\%40BETT\%20Final\%202.0.pdf (accessed 17/2/2017).

[30] OECD (2013). OECD skills outlook 2013: First results from the survey of adult skills. Paris: OECD Publishing.

[31] Pelttari, S. \& M. Mutta (2014). Language learners' seeking paths and strategies: one dimension of digital literacy. In M. Mutta, P. Lintunen, I. Ivaska, \& P. Peltonen (eds.), Tulevaisuuden kielenkäyttäjä. Language users of tomorrow. AFinLA Yearbook. Jyväskylä: Jyväskylän yliopistopaino, 157-175.

[32] Peters, E. (2007). Manipulating L2 learners' online dictionary use and its effect on L2 word retention. Language Learning \& Technology 11, 36-58

[33] PISA 2015. Assessment and analytical framework: Science, reading, mathematics and financial literacy. http://www.oecd.org/publications/pisa-2015-assessment-and-analytical-framework-9789264255425-en.htm (accessed 15/7/2016).

[34] Schmitt, N., Schmitt, D. \& C. Clapham (2001). Developing and exploring the behavior of two new versions of the Vocabulary Levels Test. Language Testing 18.1, 55-88.

[35] Schmitt, N., Jiang, X. \& W. Grabe (2011). The percentage of words known in a text and reading comprehension. The Modern Language Journal 95, 26-42.

[36] Schmitt, N. \& D. Schmitt (2014). Reassessment of frequency and vocabulary size in L2 vocabulary teaching. Language Teaching 47.4, 484-503. doi:10.1017/S0261444812000018.

[37] Singer, G., Danilov, D. \& U. Norbisrath (2012). Complex search: aggregation, discovery and synthesis. Proceedings of the Estonian Academy of Sciences 61.2, 89-106.

[38] Statistics Finland. (n.d.). Internet usage for searching for information on Wikipedia or other online encyclopedias in Finland in Q1 2015, by age group. In Statista - The Statistics Portal. https://www.statista.com/statistics/551756/internet-usage-forsearching-for-information-by-age-group/ (accessed 23/3/2017).

[39] Tono, Y. (2011). Application of eye-tracking in EFL learners' dictionary look-up process research. International Journal of Lexicography 24.1, 124-153. doi:10.1093/ijl/ecq043.

[40] Van Dijk, J. \& A. Van Deursen. (2014). Digital skills. Unlocking the information society. Basingstoke: Palgrave Macmillan.

Marja-Leena Niitemaa is a doctoral student at the Department of English, University of Turku, Finland. She has taught English at upper secondary school level and worked as a developer and teacher of English CLIL classes in the Turku area. Her research interests include vocabulary learning and teaching, computer assisted language learning, and the integration of personal face-to-face communication and digital learning. Focusing on vocabulary learning, she has contributed to a volume on foreign language learning and teaching aimed at practising language teachers and teacher trainees.

Päivi Pietilä is Professor of English at the University of Turku, Finland, where she is responsible for the SLA section of her department. Her publications include The English of Finnish Americans (1989), L2 Speech (1999), Lexical Issues in L2 Writing (2015, co-editor), in addition to a number of journal articles. Her research interests include second language acquisition and attrition, vocabulary acquisition and use, L2 academic writing, L2 speaking skills, and the lexis-grammar interface. 